\title{
ESTILO E MARCAS LINGUÍSTICAS: duas faces de um mesmo enunciado
}

\author{
Eliane Pereira Santos \\ (Universidade Federal do Maranhão) \\ https://orcid.org/0000-0002-0515-4143
}

RESUMO

Esse artigo objetiva analisar o estilo do gênero comentário online numa perspectiva sociológica. Neste contexto argumentamos a favor de que o estilo se concretiza nas escolhas linguísticas orientadas tanto pela forma, quanto pelo conteúdo e, especialmente pela posição axiológico-dialógica do comentador. Para Bakhtin (1976[1926]), dependendo do conteúdo e da imagem que se faça do ouvinte, o falante faz suas escolhas linguístico-estilísticas, definindo o estilo do enunciado. Assim, questionamos de que modo as relações de interação direcionam o estilo no gênero comentário online. Adotamos como corpus: comentários sobre notícias online, que tratam do processo de impeachment da presidente Dilma Rousseff, a partir de uma notícia retirada do portal Terra, cuja manchete é: Dilma se reúne com juristas contrários ao impeachment, publicada em 07/12/2015. Como resultado, percebemos que o estilo no gênero comentário online se constitui a partir das relações dialógicas e do posicionamento axiológico do sujeito falante, que faz as escolhas dos recursos linguístico-estilísticos (gráficos, lexicais e gramaticais), orientado pelo contexto extraverbal e pelo gênero discursivo.

PALAVRAS-CHAVE: Dialogismo; Axiologia; Estilo; Comentário online. 


\section{LINGUISTIC STYLE AND BRANDS: two faces of the same statement}

\section{ABSTRACT}

This article aims to analyze the style of online comment genre from a sociological perspective. In this context, we argue that style is embodied in the linguistic choices oriented both by form and content, and especially by the axiological-dialogical position of the commentator. For Bakhtin (1976 [1926]), depending on the content and image of the listener, the speaker makes his linguistic-stylistic choices, defining the style of the utterance. Thus, we question how the relations of interaction direct the style in the online comment genre. We adopt as corpus: comments on online news, which deal with the impeachment process of President Dilma Rousseff, from a news withdrawn from the portal Terra, whose headline is: Dilma meets with lawyers against impeachment, published 12/12/2015 . As a result, we perceive that the style in the online commentary genre is based on the dialogical relations and the axiological positioning of the speaking subject, who makes the choices of the linguistic-stylistic resources (graphical, lexical and grammatical), guided by the extraverbal context.

KEYWORDS: Dialogism; Axiology; Style; Online Review. 


\section{Introdução}

Nesta pesquisa trataremos do estilo do gênero comentário online sobre notícias, caracterizando-o não como um estilo próprio de um autor específico, mas sim, como sendo resultante de uma orientação social, veiculada a um ouvinte real ou presumido, no contexto de interação próprio do gênero comentário online. Volochínov (2013 [1926], p. 190) ao referir-se à influência da cultura dos interlocutores e da amplitude do seu horizonte ideológico, afirma: “[...] a orientação social da enunciação tem um papel decisivo para a construção da estrutura estilística".

Enfatizamos que o estilo está atrelado às escolhas feitas pelo falante. Entretanto, também são influenciadas pelo destinatário e pelo próprio gênero, uma vez que o falante, por ser resultado de uma construção social, já traz em si orientações construídas socialmente, que lhe indicam muitos aspectos estilísticos do gênero e, consequentemente, das possíveis enunciações e escolhas linguísticas.

O discurso da vida real é sempre dialógico, no qual estarão presentes no mínimo duas vozes, a do falante e a do ouvinte. Aquele que fala sempre tem em vista um interlocutor. A palavra viva nunca é proferida no vazio, desconectada da palavra do outro. Desse modo, a palavra é sempre fruto de uma atitude responsivo-avaliativa do falante. Portanto, na comunicação real, as marcas gramaticais, que são sempre selecionadas na comunicação viva, serão também sempre marcas estilísticas, já que o estilo é resultado da relação entre o eu e o outro(s).

\section{Estilo: um posicionamento axiológico-dialógico}

Bakhtin (2003[1979]) diz que o grande estilo não é casual, mas sim uma visão de mundo que pode perpassar diferentes artes, no caso da obra literária. "O grande estilo abarca todos os campos da arte ou não existe, pois ele é, acima de tudo, o estilo da própria visão de mundo e só depois é o estilo da elaboração do material". Considerando esse pensamento na vida prática, podemos dizer que sendo o estilo uma visão de mundo, não tem como ser abstraído da vivência, da experiência, das relações dialógicas. Desse modo, o tom emotivo-volitivo que perpassa o dito, expressa a unicidade de um sujeito dialógico, formado nas relações de interação que mantém com os outros, um sujeito inacabado que vive num mundo inacabado, sempre pronto para novas valorações, novos acréscimos, um mundo em permanente processo de constituição. 
O tom emotivo-volitivo se dá precisamente em relação à unidade singular concreta no seu conjunto, expressa a inteira completude do estado-evento em um momento preciso, e o expressa como o que é dado e como o que está por ser concluído - a partir do interior de mim enquanto participante obrigatório (BAKHTIN, 2012[1920-1924], p. 90).

$\mathrm{Na}$ teoria dialógica a ideia de acabamento remete à possibilidade de continuidade. O sujeito falante termina seu enunciado, deixando-o como abertura para a resposta. Característica essa que é muito perceptível no gênero comentário online, em função da forma desse gênero sempre possibilita a continuidade da cadeia comunicativa pela inserção de novos comentários ao longo do tempo. Essa possibilidade de resposta é motivadora das escolhas linguísticas do sujeito falante, uma vez que este presume possíveis réplicas para seu enunciado.

Portanto, o estilo não pode ser visto enquanto algo que pode ser analisado em sua materialidade, desnudo de uma valoração apreciativa, como um arranjo material desvinculado do contexto extraverbal, ao contrário, o estilo também é resultado de uma relação interessada entre o falante e destinatário. $\mathrm{O}$ estilo orienta a compreensão, expressa uma visão de mundo, que é ao mesmo tempo a visão de um todo (mundo cultural) e a visão de um ser-evento, que em sua unicidade, acentua o discurso tornando-o único e irrepetível. O estilo expressa um ponto de vista, que se materializa nas escolhas linguístico-expressivas. Ele aponta para um ponto de vista que nasce e cresce no confronto com outros pontos de vista, conforme afirma Bakhtin (2014[1924], p. 29): "Este ou outro ponto de vista criador, possível ou realizado de fato, só se torna necessário e indispensável de modo convincente quando relacionados com outros pontos de vista criadores [...]." O ponto de vista nasce como necessidade de uma resposta, é alimentado em suas fronteiras pela existência e diversidade de outros pontos de vista, que o tornam visível.

O estilo não pode ser tido apenas como a elaboração do material, uma vez que o antecede enquanto visão de mundo. Portanto, não é neutro, carrega a expressão da unicidade do sujeito falante. Vale ressaltar, que não estamos falando de um estilo individual, capaz de identificar o sujeito falante como autor de dado enunciado, mas daquele estilo capaz de revelar uma entonação (valoração apreciativa) do sujeito falante, o modo como ele organiza a sua voz e as vozes dos outros no seu discurso, o modo como expressa sua intenção, sua relação com ouvinte a partir do seu existir-evento em um dado gênero discursivo. 
O lugar único, espacial e temporal, ocupado pelo sujeito falante, vai ser sua diretriz valorativa sobre suas atitudes responsivo-avaliativas. É a luz que vai guiar seu olhar e sua compreensão daquilo que pode ser visto por muitos, mas nunca com a mesma valoração axiológica. Essa valoração é o que dentro de um estilo considerado enquanto visão de mundo possibilita uma singularidade responsável, uma vez que eu assumo a responsabilidade por esse lugar ocupado por mim e, que não pode ser ocupado por mais ninguém. Nenhum outro pode ter as mesmas experiências que eu, não pode viver o que eu vivi do mesmo modo.

No livro Teoria do Romance I, Bakhtin (2015[1934-1936], p. 51), ao falar sobre o discurso no romance, explicita: "A orientação dialógica do discurso é, evidentemente, um fenômeno próprio de qualquer discurso [...]. Para o prosador, o objeto é o ponto de concentração de vozes heterodiscursivas ${ }^{1}$, entre as quais deve ecoar também sua própria voz." Podemos entender que essa voz que ecoa entre as outras é sustentada pelo tom apreciativo de um sujeito que se manifesta em sua singularidade, criando um discurso atualizado, que não é igual a nenhum outro, haja vista que sua atualização aconteceu a partir de um enfoque volitivo-emocional que coloca em cena a experiência vivida de um sujeito, que também não é igual a nenhum outro sujeito.

Para Bakhtin (2003[1979]), não existem enunciados puros, uma vez que, todo enunciado surge como uma atitude responsiva do falante frente a algo já dito, ao tempo em que também busca a continuidade da cadeia comunicativa, suscitando nova resposta. A depender do gênero, teremos diferentes modos de organização dessas vozes, podendo ser mais ou menos persuasivas (dialógicas) ou consensuais (monológicas). Contudo, Volochínov (2013 [1926], p. 163) ao falar dos diferentes tipos de discursos diz que não existe uma enunciação completamente monológica: "todas essas enunciações têm de monológico sua forma externa. Sua essência, sua construção semântica e estilística são dialógicas." Assim, o dialogismo é inerente a qualquer manifestação de linguagem em situações reais de uso, em maior ou menor grau.

\footnotetext{
1 No prefácio de Teoria do Romance I: a estilística, Paulo Bezerra esclarece o uso do termo "hereodiscurso" nessa tradução. Segundo ele; "No Brasil consagrou-se o termo 'heteroglossia' como tradução da palavra russa raznorétchie, que significa 'diversidade de discursos' ou 'heterodiscurso', minha opção ao traduzir. O termo também foi traduzido como 'plurilinguísmo', que é mais palatável ao leitor brasileiro, porém difere semanticamente do original russo e do sentido que Bakhtin lhe atribui".
} 
Conforme a teoria dialógica não há palavra neutra, haja vista que todo dizer é ideológico, formado por signos que nascem no meio social, nas relações axiológico-dialógicas, que são relações de sentido e de valor. Em meio a essas relações, os discursos se cruzam em zonas de divergências ou consonâncias em relação à fala do outro. A ironia, por exemplo, revela um sentido mascarado pelo verbal, mas revelado pelo conhecimento compartilhado e por uma entonação determinada pelo contexto extralinguístico. A compreensão responsiva sobre o sentido da ironia descortina um sentido outro, que é um encontro dialógico entre autor e leitor. Para Santos; Marques; Rodrigues (2018, p. 37), “[...] a ironia é uma estratégia discursiva cuja trama se constrói principalmente sob o pilar do fingimento e cuja função mais genérica é exatamente o contorno impreciso, dúbio, da relação do enunciador com o seu enunciado".

O sujeito que ironiza responde a um já dito, entrando em conflito com ele. No discurso irônico, temos duas vozes, aquela refutada, a quem se responde de forma conflituosa, e aquela que responde. A existência do enunciado enquanto resposta é marca do dialogismo interlocutivo, presença de uma alteridade enunciativa entre a voz que é retomada e a voz do que responde, reacentuando esse dizer ironizado no plano da divergência. Essa alteridade entre a voz do ironizado e do autor da ironia marca uma alteridade interlocutiva (enquanto resposta) e uma alteridade interdiscursiva - discurso atualizado a partir da voz retomada - o discurso irônico.

Cunha (2011), ao analisar as formas de alteridade nas cartas de leitores, refere-se ao dialogismo interlocutivo e ao dialogismo interdiscursivo. No primeiro caso, temos o discurso direcionado ao outro (um interlocutor real ou presumido), já no dialogismo interdiscursivo temos o entrecruzamento de diferentes vozes em um mesmo discurso que polemizam o texto que lhe deu origem. Nesse sentido, em relação ao comentário online, seguimos o entendimento de que o discurso interlocutivo é resultado da interação entre os leitores, portanto o evento deflagrador é, geralmente, outro comentário da sequência (comentário de outro comentador). Já em relação ao dialogismo interdiscursivo temos, como evento deflagrador do comentário online, o texto, ou acontecimento que lhe deu origem.

Authier-Revuz (2011) propõe que o dialogismo interlocutivo e o dialogismo interdiscursivo não sejam descritos numa relação de oposição, mas como dois aspectos solidários, que se articulam na referência a um locutor, que se dirige a um destinatário e a um já-dito. Desse modo, o 
dialogismo interlocutivo não pode se fechar na interação direta entre um "eu" que fala e um "tu" que ouve e responde, como se ambos estivessem isolados da grande corrente da comunicação humana, que liga o dito ao já-dito. A interlocução é marcada pela interação entre um falante e um ouvinte (mesmo que apenas presumido). Esses dois elementos são parte constitutiva de todo e qualquer discurso.

Sobre a análise de comentários na web, Cunha (2012) explicita que no dialogismo interdiscursivo temos uma maior criticidade, uma vez que o comentador dialoga com as muitas vozes existentes no texto fonte, não dirigindo, portanto, a sua fala a um interlocutor em específico.

Conforme a teoria bakhtiniana, todo enunciado tem uma orientação social, uma vez que é dirigido a um ouvinte real ou imaginário, intenciona sempre uma resposta, e sua entonação é também orientada por essa possível réplica. $\mathrm{O}$ enunciado surge como resultado de uma compreensão avaliativa de um autor para outra compreensão avaliativa que tem na ponta do fio discursivo um ouvinte, pronto para avaliar e dar continuidade a cadeia comunicativa.

Volochínov (2010[1929-1930]) afirma que não há enunciação sem valoração apreciativa. Todo enunciado aponta para uma posição axiológico-dialógica do sujeito falante, que é um posicionamento voltado tanto para singularidade, uma vez que é dito por alguém em sua existência única, como também voltado para o social, haja vista que mesmo em sua singularidade esse sujeito é constituído socialmente, portanto, toda palavra é individual e social ao mesmo tempo.

Atribuir um nome é antes de tudo assumir um compromisso, um posicionamento responsivo frente a uma necessidade de valorar um objeto para mim e para o outro. Ao nomear o objeto, o falante mantém com ele uma atitude interessada, axiológica. Nesse objeto nomeado são depositadas valorações apreciativas de admiração, desprezo, aproximação, distanciamento, desejo, refutação, aceitação, ódio, alegria, nojo, indignação, e tantos outros valores possíveis. Faraco (2017) ao referir-se ao acento valorativo da palavra na teoria dialógica, explicita a impossibilidade de dizer sem valorar:

Para Bakhtin é impossível separar, em termos absolutos e abstratos, juízos factuais de juízos valorativos. A saída para o eventual impasse epistemológico quanto à validade de juízos cognitivos que inevitavelmente refratam o mundo se dá pelo confronto, pelo embate das diferentes posições axiológicas que atuam no recorte e no dizer sobre o objeto (FARACO, 2017, p. 51). 
Os nomes não são inocentes, desinteressados no uso da linguagem, ao contrário carregam sentidos, e se colocam como potencialidade para novas valorações, atualizações em diferentes situações de comunicação. Portanto uma escolha linguística ou lexical não é apenas uma materialidade verbal, mas sim, uma atitude capaz de expressar um juízo de valor.

\section{Escolhas linguísticas: um posicionamento axio- lógico-dialógico na construção estilística do gênero co- mentário online}

Veremos na análise, que ora segue, o quanto o estilo não está atrelado apenas aos recursos gramaticais, mas primeiramente e principalmente a posicionamentos axiológico-dialógicos do sujeito falante frente a uma orientação social, sendo resultante de uma resposta emotivo-avaliativa a outros discursos na corrente viva da comunicação, envolvendo todo um contexto extraverbal. Desse modo, nossas análises pretendem apontar para a importância das relações dialógicas na construção do estilo no gênero comentário online. No quadro 1 , temos a notícia que deu origem aos comentários analisados:

Quadro 1: Notícia: Portal Terra.

\section{Dilma se reúne com juristas contrários ao impeachment}

(Publicada em 07/12/2015)

A presidenta Dilma Rousseff se reuniu hoje com mais de 30 juristas para tratar do pedido de abertura do processo de impeachment, aceito pelo presidente da Câmara dos Deputados, Eduardo Cunha (PMDB-RJ) na semana passada. O grupo de juristas é contrário ao processo.

O encontro ocorreu no Palácio do Planalto. Segundo nota divulgada pelo grupo de juristas, participaram do encontro estudiosos da Constituição brasileira, professores universitários, acadêmicos, advogados e pensadores do Direito no país.

"Parte desses juristas já emitiu pareceres sobre o assunto, alguns após consulta realizada por Flávio Caetano (que foi coordenador jurídico da campanha à reeleição da presidenta Dilma Rousseff), que compõe o grupo de advogados da presidenta Dilma no impeachment", informou o comunicado.

Os demais juristas que emitiram pareceres, conforme a nota, elaboraram suas peças jurídicas por livre iniciativa, "ante a gravidade da situação política na- 
cional, que acendeu o alerta de sérios riscos ao Estado Democrático de Direito com a abertura do processo sem base legal".

O grupo informou ainda que nenhum parecer foi contratado. "Todos são gratuitos e surgem da preocupação com os rumos do país. Todos opinam contrariamente à abertura do processo, por não estarem presentes, no pedido recebido pelo deputado Eduardo Cunha, os requisitos constitucionais e legais necessários para configurar um eventual crime de responsabilidade cometido por Dilma", concluiu o comunicado.

Fonte: Disponivel em: http://noticias.terra.com.br/brasil/politica/impeachment/ dilma-se-reune-com-juristas-contrarios-ao-impeachment,94b6da9f6be275ed88d2 15f40a61f50088y9u5ge.html. Acesso em: 12/03//2016

Devido a uma necessidade de economia de espaço, fizemos um recorte, selecionando uma sequência com seis comentários a serem analisados no quadro 2, seguindo uma ordem de publicação do primeiro ao sexto comentário. Esse critério de recorte nos permitiu garantir a relação dialógica interlocutiva e interdiscursiva entre os discursos. Os comentários foram copiados e colados conforme escrita original.

\section{Quadro 2: Comentários online}

(1) Pq esses Juristas não se juntaram na época de FHC q o PT vivia dizendo q queria o impeachment, e tb do Collor??? E isso na época não era golpe pq?? Pq era o PT q queria? Pois só é golpe se for contra os ladrões do PT? Esses juristas não tem vergonha na cara ouuuuuu serà q esperam $\$$ simpatia $\$$ do governo?

\section{(2) Virginia Bea}

KKKKKKKKKKKKkkkk Quem acredita q será gratuíto????? Ta bom, ves ainda acham q a gente acredita em vocês? KKKKKKKKKKKKKK

\section{(3) Gabriel Ueta}

O bandida mineira precisa de 30 advogados para se defender, porque tem consciência da enorme responsabilidade pela corrupção e criminalidade hedionda de seu governo ilegítimo. Isso porque aqui não há pena capital. Ainda é burra, como todo mineiro. Poderia, pelo menos, se reunir em segredo, já que é inevitável um monte de cabeças para arrumar alguma lábia que convença o STJ, ou 
que pega mal fazer isso na cara dura, induzindo o público a pensar que ela é mesmo culpada de tudo. No máximo vai prorrogar o julgamento.

\section{(4) marcos cesar souza11: Gabriel Ueta}

Menos aí, não precisa citar «mineira», ou você tem preconceito para com o povo de Minas Gerais? Da forma como escreveu, parece que tens rancor de MG (ou será que foi enrabado por algum mineiro?...) e aqui em Minas Gerais Dilma é abominada, tanto que levou fumo nas eleições aqui. Portanto, cite Dilma da forma como quiser, porém, tenha mais respeito com $\mathrm{MG}$, seu imbecil!

\section{(5) Gabriel Ueta: marcos cesar souza11}

É conceito, todo mundo sabe quem é o povo de Minas. Vale do Ribeira não fica em Minas. Aécio foi abominado em Minas, e é mineiro também. Não terei respeito com bandidos e psicopatas.

\section{(6) Tarcísio José Martins}

Apesar da matéria dizer que Dilma se «reuniu hoje com mais de 30 juristas», entendo que na verdade, Dilma se reuniu com CORRELIGIONÁRIOS, que, por sinal, falaram muita coisa errada, equivocada e eivadas de vergonhosa parcialidade.

Fonte: Disponivel em: http://noticias.terra.com.br/brasil/politica/impeachment/ dilma-se-reune-com-juristas-contrarios-ao-impeachment, 94 b6da9f6be $275 \mathrm{ed} 88 \mathrm{~d} 2$ 15f40a61f50088y9u5ge.html. Acesso em: 12/03//2016

Segundo Bakhtin (2003[1979]) todo enunciado é prenhe de resposta, direciona-se a um destinatário que lança luz sobre aquilo que será dito. $\mathrm{O}$ enunciado está sempre voltado para réplica, portanto é sempre dialógico. A escolha do material linguístico é ancorada numa possibilidade de resposta do outro, ou seja, o outro é sempre levado em conta nas escolhas linguístico-gramaticais do falante. Como se pode observar, o comentador (1) começa seu discurso usando um questionamento que aponta diretamente para uma resposta do seu interlocutor (leitor), mesmo que seja uma resposta silenciosa, sem necessariamente, inserir-se na cadeia de comentário. Ao perguntar " Pq esses Juristas não se juntaram na época de FHC q o PT vivia dizendo q queria o impeachment, e tb do Collor???, o comentador (1) traz para seu enunciado o contexto extraverbal (políti- 
co) do governo do presidente FHC e do presidente Collor, contrapondo o discurso do PT ( a favor do impeachment de FHC e Collor) ao discurso do PT no atual cenário político, que considera o impeachment um golpe, uma tentativa de tomada de poder pela oposição, mas que na época anterior não era golpe, mas sim, justiça. O comentador dialoga com o discurso que é favorável ao impeachment da presidente Dilma a partir de uma relação dialógica de apoio, assim como também, refuta o discurso outro, que é o do PT e de seus seguidores.

Por trás do questionamento do internauta, tem-se, antecipadamente, possíveis réplicas. $\mathrm{O}$ enunciado é sempre replicado, uma vez que se configura como uma atitude responsiva. Ou seja, implícita ou explicitamente o falante sempre responde a seu próprio enunciado, assim como também, visa à resposta do outro. Na sequência de questionamentos: " $E$ isso na época não era golpe pq?? Pq era o PT q queria? Pois só é golpe se for contra os ladrões do PT? Esses juristas não tem vergonha na cara ouuuuuu serà q esperam \$simpatia\$ do governo?", fica evidente a construção do ponto de vista do comentador a partir dos questionamentos que faz, levando o leitor a uma atitude avaliativo-responsiva que traz à tona o ponto de vista expresso nas perguntas retóricas do comentador, que ao fazer esses questionamentos, já tem as respostas, e por meio da escolha de recursos linguístico-estilísticos, procurar convencer o outro, mantendo uma relação dialógica de convergência com os discursos favoráveis ao impeachment e de divergência com aqueles discursos que defendem o governo da presidente Dilma.

O comentador (1) questiona e ironiza o valor semântico da palavra "golpe" para o PT, avaliando esse valor como resultado dos interesses políticos do partido. Segundo o qual, nesse contexto, golpe significa uma tentativa da oposição de tomar o poder. Contudo, o comentador argumenta, questionando por que na época de Collor e FHC o impeachment não era considerado pelo PT como sendo golpe, seguindo com os seguintes questionamentos: "Pq era o PT q queria? Pois só é golpe se for contra os ladrões do PT??”. As escolhas linguístico-estilísticas denotam a natureza social do estilo, isto é, aquele que fala, não fala sozinho, não escolhe palavras desvinculadas de um contexto extraverbal. No seu discurso tem a sua voz, mas também a voz do outro, e ainda poderíamos dizer, que a sua própria voz está impregnada pelo outro. Como diz Volochinóv (2013 [1926], p. 97), "O estilo é o homem; e nós podemos dizer; o estilo são pelo menos dois homens, ou mais exatamente, é o homem e seu grupo social 
na pessoa de seu representante ativo - o ouvinte, que é o participante permanente do discurso interno e externo do homem."

Ao questionar: "Pois só é golpe se for contra os ladrões do PT?", o internauta faz uso da palavra "ladrões". Essa escolha lexical que se constitui como marca estilística denota a avaliação negativa do comentador frente ao governo do PT, descaracteriza o sentido dado à palavra golpe pelo partido, na atual conjuntura política de processo de impeachment da presidenta Dilma e explicita o ponto de vista do comentador em relação a sua avaliação sobre o governo petista.

No enunciado "Esses juristas não tem vergonha na cara ouuuuuu serà q esperam \$impatia\$ do governo?”, o comentador faz uso de um recurso gráfico (cifrão) para expressar o ponto de vista de que os juristas apoiam o PT em busca de benefícios políticos, ou seja, de dinheiro, benefícios estes aos quais ele se refere como "\$simpatia\$". A escolha lexical e gráfica feita pelo sujeito falante dá ao estilo uma entonação axiológico-dialógica de ironia, adquirindo o valor semântico de troca, ser recompensado. O uso desse recurso gráfico-lexical é orientado pelo gênero comentário online. Bakhtin sugere uma estilística do gênero, pois o estilo não pode ser estudado desvinculado do gênero, uma vez que, a linguagem verbal se concretiza por meio de gêneros. O estilo é orientado socialmente pelas relações axiológico-dialógicas e pelo gênero. "O fato de o estilo e a linguagem terem se separado do gênero acabou redundando consideravelmente num estudo que privilegiava os tons harmônicos individuais e tendenciais do estilo, ignorando, porém, seu tom de base social". Bakhtin (2015[19341936], p. 21)

$\mathrm{O}$ gênero aponta para certas possibilidades estilísticas. $\mathrm{O}$ comentário online sobre notícias é um espaço de interatividade no qual os internautas se inserem em uma cadeia comunicativa, que embora faça uso da escrita, assemelha-se muito ao diálogo face-a-face. Nesse espaço, os usuários criam suas próprias regras de linguagem, fazendo uso de emotions, abreviações e recursos gráficos variados. As escolhas estilístico-gramaticais visam à funcionalidade da comunicação, procuram expressar a entonação pretendida, considerando que mesmo fazendo uso da escrita, tem-se um espaço de interatividade em tempo real. A seleção do material, dentre outros aspectos, é orientada pelo gênero e pelo destinatário. Para o comentador, a expressão "\$impatia\$" retoma um suposto conhecimento compartilhado de que o contexto político no Brasil é movido por corrupções, por interesses pessoais, pelas trocas de "favores". 
A forma do gênero comentário online permite a interação entre os internautas. $\mathrm{O}$ internauta se vê diante de um convite para comentar a notícia ou para interagir com outros leitores em um espaço virtual. A forma do gênero comentário online ao proporcionar diferentes possibilidades de inserção na cadeia comunicativa, funciona como orientadora de marcas estilísticas. A forma desse gênero dispõe de ferramentas capazes de oportunizar ao internauta a inserção em qualquer ponto da cadeia comunicativa, ou seja, ele pode replicar qualquer comentário, e ao comentar também pode ser replicado por qualquer outro comentador.

O comentador (2) mantém com a notícia um dialogismo interdiscursivo, contestando e ironizando a fala dos juristas aliados a Dilma Rousseff, que dizem serem os pareceres gratuitos: O grupo informou ainda que nenhum parecer foi contratado. "Todos são gratuitos e surgem da preocupação com os rumos do país” Sobre essa informação noticiada, o comentador enuncia: "KKKKKKKKKKKKkkkk Quem acredita q será gratuito????? Ta bom, vcs ainda acham $q$ a gente acredita em vocês? $K K K K K K K K K K K K K K$ ”. O comentador inicia e finaliza seu discurso por meio do riso, que para Bakhtin (2013[1940]) é um forma também dialógica, que põe em cena a voz do falante e a voz daquele que é ridicularizado, uma voz contrária a sua, aqui, (a dos petistas).

$\mathrm{O}$ riso inicial, acompanhado do questionamento "Quem acredita $\mathrm{q}$ será gratuito?????, aponta para uma resposta, mesmo que em forma de pergunta, para o ponto de vista do comentador (1) de que os jurista estejam agindo, frente ao processo de impeachment da presidenta Dilma, objetivando a aquisição de "\$impatia\$". O riso seguinte (no final do comentário) responde ironicamente o enunciado do próprio comentador "Tá bom. vcs ainda acham q a gente acredita em vocês? KKKKKKKKKKKKKK”. $\mathrm{O}$ comentador insere na sua fala a voz dos petistas, à qual desqualifica por meio do riso.

Observemos os comentários (3), (4) e (5). Neles temos, claramente, a manifestação de dialogismo interlocutivo, no qual o comentador não se refere diretamente à notícia, mas sim, replica outro comentador, mesmo mantendo um diálogo interdiscursivo com a notícia.

\section{(3) Gabriel Ueta}

O bandida mineira precisa de 30 advogados para se defender, porque tem consciência da enorme responsabilidade pela corrupção e crimi- 
nalidade hedionda de seu governo ilegítimo. Isso porque aqui não há pena capital. Ainda é burra, como todo mineiro. [...]

\section{(4) marcos cesar souza11: Gabriel Ueta}

Menos aí, não precisa citar «mineira», ou você tem preconceito para com o povo de Minas Gerais? Da forma como escreveu, parece que tens rancor de MG (ou será que foi enrabado por algum mineiro?...) e aqui em Minas Gerais Dilma é abominada, tanto que levou fumo nas eleições aqui. Portanto, cite Dilma da forma como quiser, porém, tenha mais respeito com $\mathrm{MG}$, seu imbecil!

\section{(5) Gabriel Ueta: marcos cesar souza11}

É conceito, todo mundo sabe quem é o povo de Minas. Vale do Ribeira não fica em Minas. Aécio foi abominado em Minas, e é mineiro também. Não terei respeito com bandidos e psicopatas.

O comentador (4) ao dizer "menos aí", polemiza com o ponto de vista do comentador (3) ao afirmar que assim como Dilma todo mineiro é burro. A escolha léxico-gramatical da expressão "menos aí" leva em conta o que foi dito antes pelo seu interlocutor direto, que é o comentador (3). Essa escolha linguístico-estilística é marcada por uma entonação que reprova a caracterização preconceituosa dada ao povo mineiro. Dentre as relações dialógicas evidenciadas no enunciado (4), temos o apoio ao ponto de vista que é favorável ao impeachment da presidente, mas também temos a relação dialógica de reprovação à atitude preconceituosa do outro comentador, frente ao povo mineiro.

O comentador (4) expressa sua indignação pelo preconceito manifesto na fala replicada, chamando seu destinatário de "imbecil". Essa escolha linguístico-estilística indica uma entonação capaz de marcar a singularidade do comentador, que responde a partir de sua vivência, de suas experiências, portanto, dá às suas palavras uma entonação única. A palavra "imbecil" é marcada por uma entonação irrepetível, uma vez que a palavra dirige-se aquele destinatário específico, em um dado contexto também específico, dito por um enunciador que assume sua responsabilidade no ato de responder, ou seja, essa palavra já mais seria repetida com a mesma entonação em outra situação, pois, considerando-se o sujeito falante enquanto existir-evento, este está em constante processo de constituição em relação de alteridade consigo mesmo e com o outro. 
No comentário (5) o comentador (3) volta a inserir-se na cadeia comunicativa, reafirmando seu ponto de vista em relação ao povo mineiro. Para isso, generaliza, caracterizando-o como uma voz consensual, ou seja, ele procura ancorar e fortalecer seu ponto de vista, a partir de uma voz social atribuída a todo mundo: "É conceito, todo mundo sabe quem é o povo de Minas". O uso da expressão "todo mundo", que aponta para uma voz geral, não é apenas uma escolha gramatical, antes disso houve uma atitude avaliativo-responsiva, uma intenção, que motivou essa escolha. Portanto, o recurso gramatical ao ser selecionado já possui uma aureola estilística, nunca será apenas um recurso gramatical enclausurado em sua materialidade, pois estará imerso em entonações axiológico-dialógicas. Bakhtin (2015 [1934-1936], p. 49) diz: "Ora, todo discurso concreto enunciado encontra o objeto para o qual se volta sempre, por assim dizer, já difamado, contestado, avaliado [...]". Bakhtin (2003[1979]) afirma que ao construirmos nossos enunciados não recorremos a palavras dicionarizadas, mas sim a palavras já ditas, aquelas existentes nos lábios do outro.

Esse valor contextual da palavra é constitutiva do estilo, que traz em sua essência uma orientação social. O comentador (6) insere-se na cadeia comunicativa por meio do dialogismo interdiscursivo, que é aquele que mantém uma relação dialógica com o texto fonte, nesse caso, a notícia. Ele inicia seu discurso contestando a palavra jurista usada na notícia, e propondo a substituição dessa palavra por "CORRELIGIONÁRIOS"”. A substituição de uma palavra por outra não é apenas gramatical, mas acima de tudo estilística, uma vez que revela um posicionamento axiológico-dialógico do comentador que, nesse caso, põe em dúvida a função exercida pelos citados juristas, aliados à presidente Dilma no processo de impeachment. Para o comentador eles não são imparciais, mas sim, comungam com as ideologias políticas do PT. Portanto, conforme avaliação-responsiva do comentador, a palavra "correligionários" é estilisticamente mais adequada do que a palavra "jurista" para referir-se aqueles (30 homens) citados, que exercem a função de "juristas", pois na avaliação do comentador eles estão do lado do PT, atendendo os interesses desse partido, portanto, a escolha estilístico-gramatical, ideologicamente mais adequada, é "correligionários", ao invés de juristas.

2 Segundo o dicionário Aulete digital, a palavra correligionários significa: grupo ou partido que compartilha a mesma convicção, posição ou doutrina (religiosa, política, filosófica) de outra pessoa, grupo ou partido. 


\section{Considerações finais}

É importante ressaltar que o estilo não pode ser visto como característica, totalmente, imanente ao gênero, capaz de engessar as escolhas linguísticas, nem tão pouco é característica totalmente individual de um autor. O estilo é um misto de aspectos enunciativo-discursivos e semânticos, que se alimentam e se encorpam nas relações de interação social. O estilo parte (nasce) de uma relativa estabilidade do gênero, mas se nutre e cresce da relação entre o falante e o ouvinte, molda-se conforme a intenção daquele que intenciona alcançar determinado objetivo e efeito de sentido, tendo em vista um propósito comunicativo próprio do gênero escolhido.

No comentário online, o estilo se caracteriza por uma linguagem voltada para o uso, para eficácia da comunicação em um meio (digital), que possui necessidades específicas. Os usuários não são treinados a usarem essa linguagem, pois, aprendem naturalmente participando das relações de interação com outros falantes/ouvintes imersos nas práticas de comunicação inerentes ao funcionamento do gênero comentário online.

Reiteramos que o estilo não é resultado das escolhas linguísticas, mas que as escolhas linguísticas são resultantes de um estilo de base social, que relaciona o social e o singular por meio de uma orientação axiológico-dialógica, que põe em cena um eu que se constitui a partir do outro, mas que ao mesmo tempo sempre é singular em sua existência. Portanto, o estilo é dialogicamente carregado de diferentes vozes, mas também é singular porque revela uma entonação irrepetível, própria daquele que fala em sua singularidade responsável. Singularidade esta que não pode ser assumida por nenhum outro. 


\section{REFERENNCIAS}

AUTHIER-REVUZ, J. Alteridade, dialogismo e polifonia: Dizer ao outro no já dito: interferências de alteridades-interlocutiva e interdiscursiva- no coração do dizer. Letras de Hoje, Porto Alegre, v. 46, n.1,p.6-20, jan/mar.2011.

BAKHTIN, M. M. O problema do conteúdo, do material e da forma na criação literária. In: Questões de literatura e de estética: a teoria do romance. Trad.: Aurora Fornoni Bernardini [et al.]. São Paulo: Hucitec, 2014 [1924].

Para uma filosofia do ato responsável. Trad.: Valdemir Miotello e Carlos Alberto Faraco. São Paulo: Pedro \& João editores, 2012 [1920-1924]

BAKHTIN, M. M. Teoria do Romance I: a estilística. Trad.: Paulo Bezerra. São Paulo: Editora 34, 2015 [1934-1936]

Estética da Criação Verbal. Trad.: Paulo Bezerra. São Paulo: Martins Fontes, 2003[1979]

CUNHA, D. A. C. Formas de presença do outro na circulação dos discursos. Bakhtiniana. São Paulo, v. 1, n.5, p. 116-132, $1^{\text {o }}$ semestre 2011. . Reflexões sobre o ponto de vista e a construção discursiva de comentários na web. Revista Investigações. Pernambuco, v. 25, n. 2, p. 21-41, julho, 2012.

FARACO, Carlos Alberto. Bakhtin e filosofia. Bakhtiniana. São Paulo, v.12, n. 2, p.45-46, maio/ago. 2017.

SANTOS, André Cordeiro; MARQUES, Girllaynne Gleyca Bezerra dos Santos; RODRIGUES, Siane Gois Cavalcanti. A ironia como zona de confronto entre diferentes vozes/dizeres em comentários do Facebook. Bakhtiniana, São Paulo, 14 (1): 28-50, Jan./Mar. 2019.

VOLOCHINOV, V.N. Discurso na vida e discurso na arte. In: A construção da enunciação e outros ensaios. Trad.: João Wanderley Geraldi. São Paulo: Pedro \& João editores, 2013 [1926].

. Marxismo e filosofia da linguagem. Trad.: Paulo Bezerra. São Paulo: Hucitec, 2010[1929-1930].

Recebido em: 18/01/2019

Aceito em: 06/06/2019 